\title{
Language Attitude of Pashto Speakers towards English
}

\author{
* Dr. Syed Shujaat Ali, Chairman / Assistant Professor (Corresponding Author) \\ ** Dr. Ghani Rahman, Assistant Professor \\ *** Shahabullah, Lecturer
}

\begin{abstract}
The present study is concerned with the investigation of the language attitude of Pashto speakers towards English. The study aims to look into issues of language interplay of Pashto language with the English language. The study took the data from undergraduate level students through a questionnaire and found out that most of the speakers have a positive attitude towards the English language. They are of the view that through the English language they explore the world more and more because most of the materials are available in the English language and by learning it one can express himself. They opined that the government should declare English as the official language of the state once again because it is still the medium of instruction in most parts of the country. This shift of change of the official language created difficulty in learning, though they are of the view that we can contribute to society without English.
\end{abstract}

Keywords: Language Attitude, English Language, Medium of Instruction, Official Language Introduction

\section{Language Attitude}

The word attitude is derived from the Italian word which means fitness, posture. The word attitude was considered an abstract mental concept less than a century ago. Previously, the word attitude was only considered as something physical or people pose which was used only when they had to take a portrait. An attitude is a method of performance, emotion, or thinking. Attitudes frequently are the product of greatest ideology, ideas, and views. Baker (1992) has identified a large number of variables in the study of language attitudes. He considers that sex, age, language, and sociocultural and as well as background play a key role to control people's attitudes. Attitude is a way in which someone thinks or feels about someone or something. Brown (2001), attitude is considered by a huge quantity of expressive involvement such as feelings, personality, or relations in the community. Likert (1932), cited in Gardner (1980), defines that the word attitude as something like "an inference which is made based on a complex of beliefs about the attitude towards the object". Gardner (1980) elaborates on Likert's definition as "the total of a man's instructions and feelings, prejudice or bias, fix notions, worries, intimidations, and convictions about any specified topic". Ajzan (1988) defines attitudes as "a disposition to reply satisfactorily or unsatisfactorily to an object, somebody, institute, or occasion". But according to Baker (1992), it is "a theoretical concept which is used to clarify the direction and persistence of human behavior".

\section{Attitude and Language Learning}

Learning is not possible without students having a positive attitude towards it. Attitude toward the languages and attitude itself are viewed as components of motivation in language. Some of the studies found information about what the attitude of the people towards languages are; others discovered the factors of attitudes, i.e. what brings the changes in the attitude of the people (Al-Magid \& Al-Mamun, 2009). Brown (1994)-added that attitudes are like tools which carry types of aspects which are related to the development of cognition and as well as the development of affect in human beings, and it is related to the situations which develop early in childhood and are the result of parents' and peers' attitudes, connected with those people who do not know each other in several ways and interacting

\footnotetext{
* Department of English, Kohat University of Science \& Technology, Kohat

Email: s_shojaat_ali@yahoo.com

** Department of English, Hazara University, Mansehra. Email: ghani.rahman@ @u.edu.pk

*** Department of English, Kohat University of Science \& Technology, Kohat

Email: shahabullah@kust.edu.pk
} 
with affective factors in the human experience. It looks clear that various stimulants lead to a positive or negative attitude. When the attitude is positive, it leads to the exhibition of positive behavior towards studying, and also absorbing themselves in it, and determined to learn more and more. These people are also observed to display more enthusiasm which is helpful to solve a lot of problems, and also helpful to know that which things are useful to acquire for daily life, and also to engage themselves emotionally (Kara, 2009).

Attitude can be viewed from three dimensions concerning aspects of it. Every one of these dimensions has different features to take out the language attitude's results, i.e. behavioral, cognitive, and effective. These three attitudinal parts are founded in the three theoretical approaches of behaviorism, cognitivism, and humanism, correspondingly (p. 168). Attitudes might be connected to life experiences. It can impact success or failure in learning. Baker (1992) states that from a psychological point of view, attitude is a mental state of willingness to answer to something which is based on experience and also which influences posterior behavior that depends on a specific object. Lambert and Gardner (1972) have recognized two key roles of attitudes: The first one is Instrumental attitudes and the second one is Integrative attitudes.

\section{Instrumental Attitudes}

Instrumental attitude is one of the basic components of Lambert and Gardner points which are related to the wish to have social status recognition or cost-effective benefits. Instrumental attitude is a type of attitude which refers to a display attitude to a specific language for self-achievement and appreciation. Hohenthal (2003) connected instrumental attitude with Indian people and says that the Indian people use instrumental attitude mostly for good jobs opportunity and for education. People support the language when they find that a particular language is beneficial for us and that particular language is a tool to achieve extraordinary position and also that language which is beneficial in economic advantage as well as basic safety and survival and matters related to self-orientation (Baker, 1992).

\section{Integrative Attitudes}

Integrative Attitude is the second basic component of Lambert and Gardner's points related to the wish to be integrated with another language community. Both instrumental attitude and integrative attitude play the key roles in learning a language and also these roles describe the level of students concerning their situation in which they are learning the language. Instrumental attitude is the type of situation in which a student learns a language only for his interest, and an integrative attitude is not like an instrumental attitude. Integrative attitude is another type of attitude which students use when they learn a language with the wish to be integrated into a specific community that speaks that language.

Attitude (along with the desire to learn a language and the effort put into it) is a part of the tripartite multifaceted inspiration to learn another language. In other arguments, following his socioeducational model, attitude is made up of the 'willingness' of the learner. Gardner describes language learning that the attitudinal component of language learning is made up of two separate parts. On the one side, he identifies the marker integrativeness to define the fact that it "returns an exposed or willing perspective concerning the other ethnic groups in general and the proper language group specifically. On the other side, he identifies the attitudes towards the learning place, i.e. the evaluative responses towards the language teacher, towards the language course, the classroom environment, the materials, etc. (Gardner, 1985: 8).

More recently, researchers have stressed the more complex attitudes, and also concentrating on the different mechanisms of the attitude itself. In the field of the research, it is commonly supposed that attitude contains three types of components: cognitive component, an affective component, and a behavioral component (Gardner and Miller, 2010; Karahan, 2007; Mantle-Bromley, 1995). In these three components, the cognitive component is based on beliefs or perceptions about the objects or situations related to the attitude. Cognition has the types of attitude in which a person 'knows' about the exact attitudinal object, while "know doesn't imply the fact of truth" (Mantle-Bromley, 1995: 373). The next component of attitudes is 'affect' consisting of feelings about the attitudinal object. It is mostly a barometer of the mark of like or dislike which is associated with the attitudinal object (Gardner and Miller, 2010). The last one is the behavior component referring to intentions or actions related to the attitudinal object. 


\section{Objectives of the Study}

This study has the following objectives

1) To investigate the attitude of students towards the English language in Swat.

2) To find out the purposes of the students for which they learn English.

\section{Significance of the Study}

The present is significant because no study has been conducted about Pashto speakers' attitudes about the English language. The study explored in detail the perception of the Pashto speaking students about learning English. The study will help English language learners to know about the common attitudes of Pashto speakers towards English. The study will further help the courser designers to know about the needs of the students. The study will also contribute to the scholars' knowledge about the attitude of second language learners about the target language because the attitude towards the target language matter a lot in langue learning.

\section{Methodology}

\section{Population and Sample}

The nature of this research study is descriptive and the survey-based method is used to obtain the data for the study. The population of this research study is undergraduate students of the English Department at the University of Swat. Fifty male students were selected by convenience sampling from the English department of the University of Swat to participate in this study. The age of these participants vary between eighteen years to twenty-two years. All of these students had studied English Language for more than 18 years. All these students were from the English department, so they know the importance of the English language. All these students were Pashto speakers (their L1 was Pashto), so that we have a homogeneous group in terms of language background. Only those fifty students were selected who were willing to participate in the study. A convenience non-random sampling procedure was applied in the present study.

\section{Instrumentation}

A survey questionnaire was used for collecting the data. This method is chosen due to its efficacy (1) this method is feasible for empirical research; (ii) the data collected can be easily quantified ; (iii) this method gives ample time to informants to give detail and full-pledged answers; (iv) this needs less time and requires low cost and saves time. The questionnaire was designed by the researchers taking ideas from the tools of previous studies (e.g. Hohenthal, 2003) and changed according to the aims of this study. In designing the questionnaire, caution was practiced to maintain the quality and standards of the questions. The researchers were anxious about the clarity, practicality, and applicability of the tools. A sample survey was exercised to know and examine the efficacy of tools for this study. After collecting the data, SPSS was used for computation and tabulation. The frequencies and percentage values were computed through descriptive statistics in this study. The questionnaire used in the study had 13 questions about the language attitude of Pashto speakers towards English.

\section{Data Collection Procedure}

The data of this study collected through questionnaires. The researcher distributed a questionnaire among fifty students in the English department. All the participants were briefed about the objectives of the study and asked for their willing participation in this joint venture. All the students responded positively and showed their enthusiasm. The questionnaire was distributed among the participants and the researchers themselves collected the data. The ambiguous questions were explained to the participants by the researchers.

\section{Results}

The following table shows the results of the questionnaire. All the participants responded to all questions of the questionnaire. 
Table 1 showing the results of the questionnaire about attitude towards English language

The above table shows the results of the first question regarding learner attitudes towards the English language. A total of 75\% of respondents agreed and they prefer that there should be English

\begin{tabular}{|c|c|c|c|c|}
\hline S No. & Questions & YES & $\mathrm{NO}$ & Total \\
\hline 1 & There should be English speaking environment. & $75 \%$ & $25 \%$ & $100 \%$ \\
\hline 2 & English should be the medium of instructions in the classroom. & $80 \%$ & $20 \%$ & $100 \%$ \\
\hline 3 & English language is difficult in learning. & $62 \%$ & $39 \%$ & $100 \%$ \\
\hline 4 & Will the learning of English trigger your job opportunities? & $78 \%$ & $22 \%$ & $100 \%$ \\
\hline 5 & Do you enjoy English class? & $73 \%$ & $27 \%$ & $100 \%$ \\
\hline 6 & Would you explore the World more and more by learning English? & $91 \%$ & $9 \%$ & $100 \%$ \\
\hline 7 & $\begin{array}{l}\text { The English materials available in text and electronic media are of a } \\
\text { high standard in quality and quantity from the materials in other } \\
\text { languages available to me. }\end{array}$ & $88 \%$ & $22 \%$ & $100 \%$ \\
\hline 8 & $\begin{array}{l}\text { The government should declare English as the official language of the } \\
\text { state once again. }\end{array}$ & $87 \%$ & $13 \%$ & $100 \%$ \\
\hline 9 & $\begin{array}{l}\text { I prefer to introduce myself in English in certain places like seminars, } \\
\text { meetings, and official functions. }\end{array}$ & $78 \%$ & $22 \%$ & $100 \%$ \\
\hline 10 & I gain more confidence in learning and speaking English. & $78 \%$ & $22 \%$ & $100 \%$ \\
\hline 11 & I feel shy while speaking in English before the public. & $81 \%$ & $19 \%$ & $100 \%$ \\
\hline 12 & I learn English because I can contribute more to society. & $69 \%$ & $31 \%$ & $100 \%$ \\
\hline 13 & $\begin{array}{l}\text { I feel disappointed when not able to express or share my ideas with } \\
\text { others in English. }\end{array}$ & $88 \%$ & $12 \%$ & $100 \%$ \\
\hline
\end{tabular}

speaking environment while $25 \%$ of respondents disagreed with the first question. The majority of the respondents $(80 \%)$ agreed that the medium of instructions should be English, however $20 \%$ of respondents disagreed with this idea of English as a medium of instruction and they responded that English is not important for the medium of instructions in the classroom. About the difficulty of learning English, the question was mostly replied in yes. Out of fifty respondents, $62 \%$ agreed that the English language is difficult in learning. While 38\% of respondents disagreed and they responded that the English language is not that difficult in learning.

About the scope of English from a market point of view i.e. job availability because of competence in English, the majority of the respondents (77.5\%) had a positive response that learning English has many job advantages in daily life. While $22.5 \%$ of respondents disagreed and they do not consider English that much important for the job. When the students were asked about their English classes, most of the respondents (72.5\%) were of the view that they always enjoyed their English class On the other hand, $27.5 \%$ did not enjoy their English class. On the contrary, when the same students were asked in the next question whether they would explore the world more and more by learning; their responses increased in favor of yes and reached $91 \%$ which was the highest number of responses in all the questions. The responses of $9 \%$ of respondents were not even in favor of this option. Similarly, when the students were asked about the quantity and quality of materials available to the students in English language, a total of $88 \%$ agreed that the materials of English available in the form of text and electronic media has both standard quality and quantity compared to the materials available in other languages. Only $22 \%$ differed with this and claimed that the materials available in other languages too have high standards in quality and quantity as like the materials in the English language.

One of the questions was about the point of view of students regarding the changing status of English as no more official language of Pakistan. About this question, the majority of the respondents (87\%) agreed English should be made the official language of the country once again. while on the other hand, $13 \%$ of the respondents disagreed with this idea and they were not in favor of English as the official language of the state. A similar question about the function of English in a global context was mostly favored in favor of English. The majority of the respondents, i.e. $78 \%$ agreed the like to communicate in English in seminars, conferences, and official meetings. Now a days English language is used at a very high level in everywhere like seminars, meetings, and as well as in official functions. Twenty-two (22\%) of the respondents disagreed that English should be put to such functions and these could be easily done in mother tongue (Pashto) or Urdu. 
The rest of the questions were about the personal use of the English language for these participants. Most of the respondents, i.e. 74\%, agreed that they gain more confidence by learning and using English. While only $26 \%$ of respondents disagree with this idea. This response to this question, particularly, shows a positive attitude towards English. These students get confidence because throw away their shyness which they get inherently from the conservative society. So, when the students were asked why they did not speak English, $81 \%$ of respondents replied that they feel shy while speaking English before the public. Only 19\% of respondents disagreed with the idea of being shy when speaking English. Similarly, when the students were asked about the importance of their learning English, 69\% agreed that they want to contribute more to the society which they can do if they know the English language. While 31\% of respondents did not consider English important for this. The last question was about the feelings of the students if they did not know English. The majority of the respondents, i.e. $89 \%$ responded they wanted to learn the English language for sharing their ideas with the people who belong to other countries; they felt disappointed if they fail to do so. Only $11 \%$ of respondents disagreed with this idea. The students knew the importance of English and so, wanted to learn and use in most of the domains, particularly, if they were to interact with foreigners.

\section{Discussion}

The results above show that Pashto speakers have overall positive attitudes towards the English language. The students are well aware of the importance of English, and so, we're in favor of English speaking environment. The environment can make sure their learning of the English language easier for them. Similarly, they know that if the medium of instruction is not English, they will have less exposure to English language input. So, they were in favor of English as a medium of instruction. This perception of the students being the medium of instruction is practically not applied in reality, particularly, at a lower level. This lack of English as a medium of instruction makes the English language difficult to learn. This unavailability of English speaking environment and as well as the lack of competent teachers further makes the situation gave and as a consequence the students consider English as a difficult language and despite learning it for so long. English is not difficult because of the available resources like interesting movies, English newspapers, English news, and as well as speaking environment.

English language is a job giver language and also provides more opportunities for people according to the respondents. They enjoyed English class because they know the importance of the English language in day to day life. They were interested in English movies, English newspapers, English news, and as well as interested in those programs which were in the English language. They had a negative response about English class because they had no interest in the English language and also they were weak in their study. They don't know English well. These students were of the view that they can explore the world more and more with the help of the English language. They know that the English language is the language of globalization and as well as the language of power. If they learned the English language, they can know about what happens in the world and can put their respective contribution in this regard.

English as a global language had standard quality and quantity in terms of the textbooks available. The use of English in every domain and walk of life, according to the participants justifies their perception to make English as the official language of Pakistan once again. These students were in the favour of English language and want the English language is the official language of the state. They know the importance of the English language and as well as the power of the English language. They know that the English language is impressive, therefore, people use this in every place so they wanted to use it in seminars, conferences, and official meetings.

They were of the view that they gain confidence by learning and using English (showing a positive attitude). These students get confidence because using English throws away their shyness which they get inherently from the conservative society. The majority of the respondents agree that they feel shy in front of the public while speaking English. Therefore they had positive attitudes towards the English language because they can contribute to society if they know a global language.

\section{Conclusion}

The presentation explored the attitude of the Pashto speakers towards the English language. The study found out that most of the speakers had a positive attitude towards the English language. They were of the view that through the English language they would explore the world more and more because 
most of the materials are available in the English language and by learning it one can express himself. They opined that the government should declare English as the official language of the state once again because it is still the medium of instruction in most parts of the country. This shift of change of the official language created difficulty in learning. The lack of a proper environment for the English language graves the situation further and the students feel shy when they speak English in front of the public creating discomfort and the students are dissatisfied with their academic performance. The findings revealed that students had a positive attitude towards the English language. The use of English, at least in the academic environment should be encouraged at academic and policy levels. The quality textbooks should be provided to the students and they should be given enough time to learn and practice English. The study will contribute to overall academic learning and planning in the global context within Pakistan.

\section{References}

Ajzan, I. (1988). Attitude, Personality, and behavior. Chicago: Dorsey Press.

Al-Magid, A., \& Al-Mamun, M. (2009). The effect of teachers' attitudes on the effective implementation of the communicative approach in ESL classrooms (Doctoral dissertation).

Baker, C. (1992). Attitude and Language. Bristol: Multilingual Matters.

Brown, H. D. (1994). Principles of language learning and teaching. London: Longman.

Brown, H. D. (2001). Principles of language learning and teaching. New Jersey: Prentice-Hall.

Gardner, D., \& Miller, L. (2010). Beliefs about self-access learning: Reflections on 15 years of change. Studies in Self-Access Learning Journal, 1(3), 161-172.

Gardner, R. (1980). On the validity of affective variables in second language acquisition: conceptual and statistical considerations. Language Learning, 30(2), 255-270.

Gardner, R. (1985). Social Psychology and second language learning: the role of attitude and motivation. London: Edward Arnold.

Hohenthal, A. (2003 3(5)). English in India, loyalty and attitude. Language in India, 3(5), 27-45.

Kara, A. (2009). The effect of a 'learning theories' unit on students' attitudes toward learning. Australian Journal of Teacher Education, 34(3), 5-9.

Karahan, F. (2007). Language attitude of Turkish students towards the English language and its use in the Turkish context. Journal of Arts and Sciences, 1(7), 73-87.

Lambert, R \& Gardner, W. (1972). Attitudes and motivations in second language learning. New York: Newbury House.

Likert, R. (1932). A Technique for the Measurement of Attitude. Archives of Psychology, 22, 5-55.

Mantle-Bromley, C. (1995). Positive attitudes and realistic beliefs: links to proficiency. Modern Language Journal, 79(3), 372-386. 